\title{
Morphologic characteristics of sacra associated with assimilation of the last lumbar vertebra
}

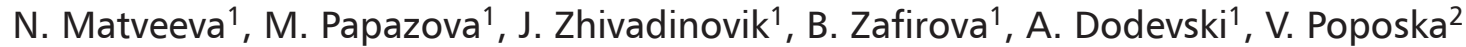 \\ ${ }^{1}$ Institute of Anatomy, University "Ss. Cyril and Methodius", Skopje, R. Macedonia \\ 2Institute of Forensic Medicine and Criminology, University "Ss. Cyril and Methodius", Skopje, R. Macedonia
}

[Received: 24 April 2015; Accepted: 1 June 2015]

Background: The impact of lumbosacral transitional states on biomechanics of load transmission between the spine and the legs has been sporadically reported. The aims of the study were to identify morphostructural alterations of sacra associated with assimilation of the last lumbar vertebra and to analyse them in the light of their biomechanical impact.

Materials and methods: Linear dimensions of sacrum, its body and base and articular surfaces were measured in 31 normal and 41 transitory sacra. Nineteen sacra presented articular and 22 osseous fusion of the last lumbar vertebra. Measured parameters were compared between normal sacra and the two variations of transitory sacra.

Results: Sacra with articular fusion of the last lumbar vertebra showed more pronounced concavity of the sacral curvature and wider than long sacral bodies. The first sacral segment was modified, broaden, ventrally wider and elevated. Almost the whole segment bore at its sides auricular surfaces. Very small portion of the segment was non-articular with less pronounced wedging. Sacra with osseous fusion of the last lumbar vertebra showed similar concavity of the sacral curvature as normal sacra, but longer than wide sacral bodies. The ventral sloping half of the newly formed first segment bore auricular surfaces. The non-articular part was enlarged with pronounced wedging.

Conclusions: The term "sacralisation" includes both types of transitory sacra with mutually different morphostructural characteristics in contrast to the normal sacra. Analysis of these morphologic variations may help in understanding the different biomechanical properties and patterns of load transmission. (Folia Morphol 2016; 75, 2: 196-203)

Key words: lumbosacral transitory vertebra, sacralisation, auricular surface, sacroiliac joints

\section{INTRODUCTION}

The last mobile functional unit of the spine is the lumbosacral unit. The lumbosacral junction transmits the axial load from the axial skeleton sideways into the pelvis (sacroiliac joints) to the appendicular skel- eton. The sacroiliac joints are essential for effective load transfer between the spine and the legs. These joints act as stress relievers and provide sufficient flexibility for the intrapelvic forces to be effectively transferred to and from the lumbar spine and lower

Address for correspondence: Dr N. Matveeva, Faculty of Medicine, 50 Divizija 6, 1000 Skopje, R. Macedonia, tel: 0038923125304, e-mail: nikimatveeva@gmail.com; nikimatveeva@medf.ukim.edu.mk 

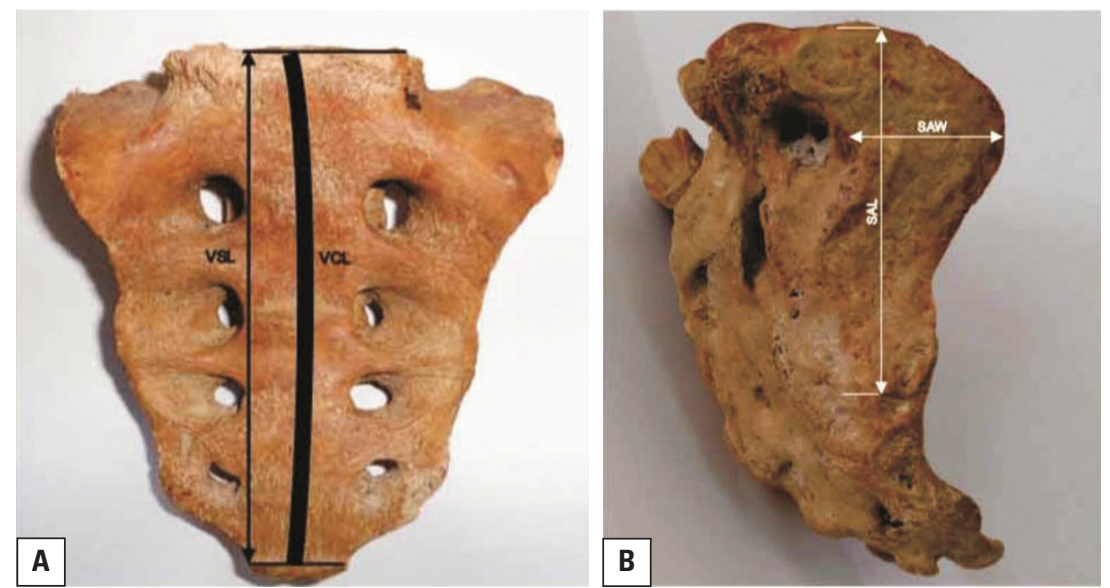

Figure 1. A. Ventral view of sacrum with accessory articular surface; VSL — ventral straight length from midpoints of promontory to the inferior border; VCL — ventral curved length from midpoints of promontory to the inferior border; $\mathbf{B}$. Lateral view of the same sacrum showing the auricular surface. Note that superior limb occupies most of the first sacral segment, extending backwards above the level of the sacral vertebral body; SAL — straight auricular length; SAW — straight auricular width.

extremities [20]. The morphostructural characteristics of these components reflect the biomechanics of load transmission and the range of movements.

The vertebra lying at the juncture of lumbar and sacral spinal segments frequently exhibit characteristics of the neighbouring vertebral class - transitional lumbosacral vertebra. Alterations in vertebral number and identity often affect the lumbosacral region, where the last lumbar vertebra may form joints with the sacrum bellow (articular fusion) or may become completely incorporated into the sacrum (osseous fusion), therefore reducing the number of lumbar vertebra. The incidence of this common anatomical variation is between $4 \%$ and $30 \%$ in general population [6]. The last vertebra and the first sacral segment can fuse at one or more locations (transverse and costal processes, vertebral bodies or zygapophyseal joints). Controversial opinions exist regarding the clinical significance of this entity $[4,9]$. Presence of new lumbosacral articular interfaces unilaterally or bilaterally leads to altered load transmission and affects not only the intervertebral discs, but the zygapophyseal joints as well. It has been widely accepted that lumbosacral transitory vertebra alter the biomechanics of the spine and contribute to low back pain [13].

The aims of the study were to identify morphostructural characteristics of sacra with articular and osseous fusion of the last lumbar vertebra (sacralisation), to compare their varying morphology with the normal sacra and to analyse these morphologic alterations in the light of their biomechanical impact.

\section{MATERIALS AND METHODS}

A total of 72 dried human adult sacra without breakage obtained from the osseous collection of the Institute of Anatomy and the Institute of Forensic Medicine and Criminology were selected for the study. An approval to conduct the study was obtained from the Institutional Review Board of the University Clinical Centre. Selected sacra were normal specimens with 5 segments (31) and transitory sacra associated with assimilation of the last lumbar vertebra. Transitory sacra were divided in two groups: sacra with 5 segments with unilateral and bilateral articular fusion of the last lumbar vertebra (19), and sacra with 6 segments (22 specimens), due to unilateral and bilateral osseous fusion of the last lumbar vertebra.

Digital sliding calliper with accuracy of $0.01 \mathrm{~mm}$ was used for measuring linear dimensions. For measuring curved distances Doctor's tape (Micropore) was used. Articular surfaces were measured by tracing their outlines on self-adhesive transparent paper completely covering uneven articular surfaces. The articular areas were then calculated on a flat surface with the help of digital planimeter.

Linear and curved measured dimensions on the sacral vertebral body and its base were: 1) midventral straight length (VSL) - straight length between the midpoints of the sacral promontory and the antero-inferior sacral border; 2) midventral curved length (VCL) - curved median length along the ventral sacral surface between the midpoints of the sacral promontory and the antero-inferior sacral border (Fig. 1). 


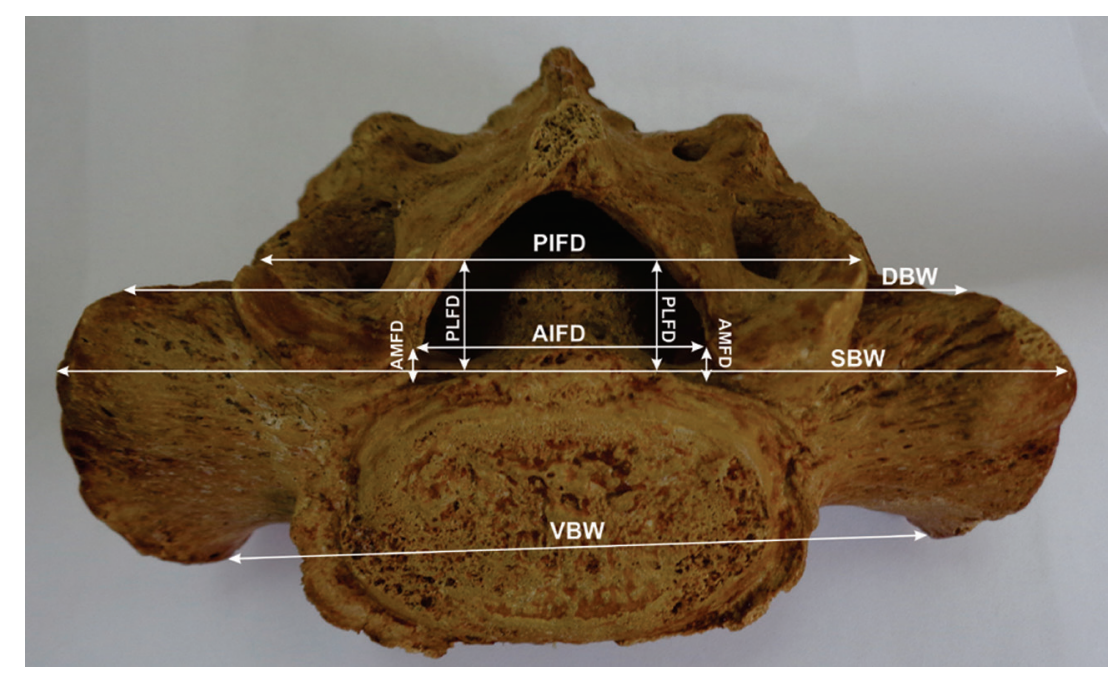

Figure 2. Base of sacrum with accessory articular surface; VBW — ventral base width; SBW — superior base width; DBW — dorsal base width; AIFD — anterior interfacet distance; PIFD — posterior interfacet distance; AMFD — anteromedial facet depth; PLFD — posterolateral facet depth.

On the upper surface of the first sacral segment, comprising the two ala following distances were measured: 1) superior base width (SBW) - maximum transverse distance between the dorsocranial edges of the auricular surfaces; 2 ) ventral base width (VBW) maximum transverse distance between the coalesce of the superior and inferior limbs of the auricular surfaces; 3 ) dorsal base width (DBW) - minimum transverse distance on the dorsal part of the sacral base borne by the transverse elements (Fig. 2).

The following indices were computed in order to determine morphostructural features of the sacral body and its base:

1) longitudinal curvature index (LCI) - VSL/VCL $\times 100$;

2) ventral base index $(\mathrm{VBI})-\mathrm{VBW} / \mathrm{SBW} \times 100$;

3) dorsal base index (DBI) - DBW/SBW $\times 100$;

4) sacral body index (SBDI) - VBW/VSL $\times 100$.

Linear measurements made on the articular surfaces were: 1) sacral vertebral body width (SVBW) maximum transverse diameter of the articular surface of the body of the first sacral segment; 2) sacral vertebral body depth (SVBD) - maximum antero-posterior diameter of the body of the first sacral segment, and 3) straight length of the auricular surfaces (R/L SAL) — right/left maximum straight length of the auricular surfaces; 4) straight width of the auricular surfaces (R/L SAW) - right/left maximum straight width of the auricular surfaces (Fig. 1).

The orientation of the superior articular facets with respect to the sagittal plane was defined with a line parallel to the average plane of the joints passing through the most anteromedial and posterolateral limits of the facet joints. The position and the orientation of the superior sacral articular facets was assessed by measuring: 1) anterior and posterior interfacet distance (AIFD/PIFD) — transverse distances between the anteromedial and posterolateral limits of the superior sacral articular facets; 2) anteromedial and posterolateral facet depth (R/L AMFD, R/L PLFD) - right/left perpendicular distances between the posterior border of the first sacral vertebral body and the coronal planes passing through the anteromedial and posterolateral limits of the superior sacral articular facets, and 3) interpedicular distance (IPD) - maximum transverse distance between the pedicles of the first sacral segment (Fig. 2).

Following articular surfaces were measured: 1) articular area of the body of the first sacral segment (SVBA); 2) superior articular facets areas, right/ /left (R/L SFA), and 3) auricular sacral articular areas, right/left (R/L ASA).

The sacra were inspected and screened for the presence of dissimilarity in the superior sacral articular facets position and/or size and dissimilarity in the auricular surfaces position and/or size. The vertical extent of the auricular surfaces according to the sacral segments was inspected and notified.

All measurements were performed by one rater on three different occasions separated in 1 week interval. Data were submitted to the intraclass correlation coefficient (ICC) to assess the measurements replicability. Differences in means between the normal and transitory sacra were statistically analysed using the Student's t test for continuous or $\chi^{2}$ test 
Table 1. Comparison of the means of linear dimensions and indices between normal sacra and sacra with articular fusion and between normal sacra and sacra with osseous fusion of the last lumbar vertebra

\begin{tabular}{|c|c|c|c|c|c|}
\hline Linear dimensions and indices of sacra & $\begin{array}{c}\text { Normal sacra } \\
\quad(\mathrm{n}=31)\end{array}$ & $\begin{array}{l}\text { Sacra with articular } \\
\text { fusion of } L 5(n=19)\end{array}$ & $\mathbf{P}$ & $\begin{array}{l}\text { Sacra with osseous } \\
\text { fusion of } L 5(n=22)\end{array}$ & $\mathbf{P}$ \\
\hline Midventral straight length (VSL) & $107.52 \pm 9.18$ & $100.16 \pm 11.03$ & $0.014^{*}$ & $116.67 \pm 15.1$ & $0.008^{* *}$ \\
\hline Midventral curved length (VCL) & $118.77 \pm 9.69$ & $116.32 \pm 8.95$ & 0.375 & $130.23 \pm 18.22$ & $0.012^{* *}$ \\
\hline $\begin{array}{l}\text { Longitudinal curvature index: } \\
\text { LCI (VSL/VCL } \times 100)\end{array}$ & $90.6 \pm 4.48$ & $86.09 \pm 6.87$ & $0.017^{*}$ & $89.85 \pm 4.38$ & 0.547 \\
\hline Superior base width (SBW) & $112.58 \pm 7.45$ & $112.7 \pm 5.83$ & 0.951 & $114.61 \pm 9.75$ & 0.394 \\
\hline Ventral base width (VBW) & $106.82 \pm 7.67$ & $109.37 \pm 5.88$ & 0.221 & $107.55 \pm 7.99$ & 0.739 \\
\hline Dorsal base width (DBW) & $88.78 \pm 6.88$ & $91.5 \pm 7.2$ & 0.756 & $86.31 \pm 8.74$ & 0.009 \\
\hline Ventral base index: VBI (VBW/SBW $\times 100)$ & $94.96 \pm 4.51$ & $97.09 \pm 3.31$ & 0.082 & $93.98 \pm 3.69$ & 0.408 \\
\hline Dorsal base index: $\mathrm{DBI}(\mathrm{DBW} / \mathrm{SBW} \times 100)$ & $79.08 \pm 5.53$ & $79.84 \pm 6.56$ & 0.977 & $75.45 \pm 5.62$ & 0.306 \\
\hline Sacral body index: SBDI (VBWNSL × 100) & $99.78 \pm 8.28$ & $110.51 \pm 14.39$ & $0.002^{*}$ & $93.53 \pm 12.65$ & $0.034^{* *}$ \\
\hline
\end{tabular}

All measurements are in millimetres with standard deviations; $p$ values indicate the test of significance for difference of means between normal sacra and sacra with articular fusion of $L 5$ $\left({ }^{*}\right)$ and between normal sacra and sacra with osseous fusion of $L 5\left({ }^{* *}\right)$.

for categorical variables. The significance level was set at $5 \%$. Statistical software SPSS was used $\left(20^{\text {th }}\right.$ version, Chic. IL, USA).

\section{RESULTS}

The ICC values were higher than 0.95 for the 3 repetitions of 72 measurements for each parameter with excellent replicability.

Of 19 sacra with accessory articulations 6 showed unilateral and 13 bilateral accessory articular surfaces on the elevated dorsal part of their sacral bases (transverse process element). Midventral straight length of these sacra was significantly smaller, therefore the value of the $\mathrm{LCl}$ was indicative of more pronounced concavity of the sacral curvature. Sacral body index showed wider than long sacral bodies compared to the normal sacra (Table 1). The broad ventral part of the first sacral segment bears at its lateral sides auricular surfaces for the articulations with the ilia. The part posterior to it is non-articular, roughen by the attachments of sacroiliac ligaments and wedged at its base. The superior limb of the auricular surfaces is restricted to the first segment. The configuration of the first segment (both its articular and non-articular part) was modified in sacra with articular fusion of L5. The segment at its base was broaden ventrally and dorsally. Almost the whole segment bore auricular surfaces with ventrally wider and elevated articular part. The craniodorsal edges of the auricular surfaces were moved back above the plane of the sacral vertebral body, superior limbs were almost horizontally positioned elevating the coalescence of the anterior edges of the superior and inferior limbs at the upper level of the segment. The inferior limbs ended at the lower border of S2 or the upper border of S3 segment. Increased ventral base index indicated that the divergence of the superior limbs relative to one another was reduced (Table 1). The convergence of the inferior limbs was also less pronounced; in some specimens the orientation was even reverse. Normal sacra were wider superiorly than ventrally at their bases and the auricular surfaces occupied almost 2/3 of the first segment. The auricular surfaces in normal sacra extended from the upper level of the first to the mid-level of the third segment. The dorsal non-articular wedged part was reduced in transitory sacra, much more elevated at its base, bearing accessory articular surfaces unilaterally or bilaterally. The dorsocranial wedging was less pronounced. The elevation of the auricular surfaces above the vertebral body plane enlarged their straight lengths (Table 2). The superior articular facets were oriented backwards, obliquely from medial to lateral, closer to the coronal plane. The depth of the lateral recess part of the sacral canal was reduced compared to the normal specimens (Fig. 3). The superior articular facet areas were smaller because the articular surfaces were more flat than concave (Table 3). Larger accessory articular surfaces corresponded to rudimentary, smaller superior articular facet on the same side. Most of the samples with dissimilarity in the superior articular facets size demonstrated dissimilarity in the auricular surface size (smaller superior articular facet, compensatory enlarged auricular surface area on the same side). 
Table 2. Comparison of the means of linear dimensions of sacral articular surfaces between normal sacra and sacra with articular fusion and between normal sacra and sacra with osseous fusion of the last lumbar vertebra

\begin{tabular}{|c|c|c|c|c|c|}
\hline $\begin{array}{l}\text { Linear dimensions of sacral articular } \\
\text { surfaces }\end{array}$ & $\begin{array}{l}\text { Normal sacra } \\
\quad(\mathrm{n}=31)\end{array}$ & $\begin{array}{l}\text { Sacra with articular } \\
\text { fusion of } L 5(n=19)\end{array}$ & $\mathbf{P}$ & $\begin{array}{l}\text { Sacra with osseous } \\
\text { fusion of } L 5(n=22)\end{array}$ & $\mathbf{P}$ \\
\hline Sacral vertebral body width & $48.17 \pm 3.51$ & $47.32 \pm 4.89$ & 0.479 & $50.19 \pm 5.81$ & 0.156 \\
\hline Sacral vertebral body depth & $30.79 \pm 3.14$ & $31.45 \pm 3.68$ & 0.498 & $31.81 \pm 4.33$ & 0.322 \\
\hline Sacral auricular straight width: right/left & $\begin{array}{l}25.16 \pm 3.75 / \\
/ 24.19 \pm 3.02\end{array}$ & $\begin{array}{l}25.06 \pm 4.58 / \\
/ 24.32 \pm 3.65\end{array}$ & $\begin{array}{l}0.932 / \\
/ 0.884\end{array}$ & $\begin{array}{l}24.04 \pm 3.3 / \\
/ 24.49 \pm 4.05\end{array}$ & $\begin{array}{l}0.267 \\
0.753\end{array}$ \\
\hline Sacral auricular straight length: right/left & $\begin{array}{l}59.85 \pm 4.79 / \\
/ 60.59 \pm 5.43\end{array}$ & $\begin{array}{l}63.13 \pm 5.6 / \\
/ 62.92 \pm 5.91\end{array}$ & $\begin{array}{l}0.032^{*} / \\
/ 0.161\end{array}$ & $\begin{array}{l}66.19 \pm 10.84 / \\
/ 63.68 \pm 8.57\end{array}$ & $\begin{array}{c}0.006^{* *} \\
0.114\end{array}$ \\
\hline Anterior interfacet distance & $27.26 \pm 4.82$ & $26.86 \pm 3.82$ & 0.760 & $25.29 \pm 4.88$ & 0.152 \\
\hline Posterior interfacet distance & $55.43 \pm 5.79$ & $55.25 \pm 5.34$ & 0.912 & $56.47 \pm 6.19$ & 0.980 \\
\hline Anteromedial facet depth right/left & $\begin{array}{l}7.47 \pm 1.46 / \\
/ 7.58 \pm 1.24\end{array}$ & $\begin{array}{l}7.32 \pm 1.44 / \\
/ 6.84 \pm 1.21\end{array}$ & $\begin{array}{l}0.724 / \\
/ 0.042^{*}\end{array}$ & $\begin{array}{l}8.99 \pm 1.75 / \\
/ 8.63 \pm 1.74\end{array}$ & $\begin{array}{l}0.001^{* *} \\
0.013^{* *}\end{array}$ \\
\hline Posterolateral facet depth: right/left & $\begin{array}{c}17.18 \pm 2.92) / \\
/ 16.3 \pm 2.31\end{array}$ & $\begin{array}{l}15.56 \pm 3.07) / \\
/ 15.31 \pm 2.33\end{array}$ & $\begin{array}{l}0.068 / \\
/ 0.147\end{array}$ & $\begin{array}{l}18.8 \pm 4.29 / \\
/ 18.09 \pm 3.93\end{array}$ & $\begin{array}{c}0.109 \\
0.042^{* *}\end{array}$ \\
\hline Interpedicular distance & $31.41 \pm 3.42$ & $30.73 \pm 2.7$ & 0.459 & $32.36 \pm 3.48$ & 0.328 \\
\hline
\end{tabular}

All measurements are in millimetres with standard deviations; $p$ values indicate the test of significance for difference of means between normal sacra and sacra with articular fusion of $L 5$ $\left({ }^{*}\right)$ and between normal sacra and sacra with osseous fusion of $L 5\left({ }^{* *}\right)$.

Table 3. Comparison of the means of sacral articular surface areas between normal sacra and sacra with articular fusion and between normal sacra and sacra with osseous fusion of the last lumbar vertebra

\begin{tabular}{|c|c|c|c|c|c|}
\hline Areas of the sacral articular surfaces & $\begin{array}{l}\text { Normal sacra } \\
(\mathrm{n}=31)\end{array}$ & $\begin{array}{l}\text { Sacra with articular } \\
\text { fusion of } L 5(n=19)\end{array}$ & $\mathbf{P}$ & $\begin{array}{l}\text { Sacra with osseous } \\
\text { fusion of } L 5(n=22)\end{array}$ & $\mathbf{P}$ \\
\hline Sacral vertebral body area & $11.25 \pm 1.87$ & $12.74 \pm 3.64$ & 0.114 & $12.81 \pm 3.22$ & 0.057 \\
\hline Auricular sacral areas: right/left & $\begin{array}{l}11.72 \pm 2.06 / \\
/ 11.52 \pm 2.08\end{array}$ & $\begin{array}{l}12.68 \pm 2.36 / \\
/ 12.58 \pm 1.58\end{array}$ & $\begin{array}{l}0.141 / \\
/ 0.080\end{array}$ & $\begin{array}{l}12.66 \pm 2.68 / \\
/ 12.43 \pm 2.59\end{array}$ & $\begin{array}{l}0.165 \\
0.176\end{array}$ \\
\hline Superior facet areas: right/left & $\begin{array}{l}1.87 \pm 0.33 \\
1.83 \pm 0.34\end{array}$ & $\begin{array}{l}1.77 \pm 0.48 / \\
/ 1.78 \pm 0.46\end{array}$ & $\begin{array}{l}0.385 / \\
/ 0.674\end{array}$ & $\begin{array}{l}2.16 \pm 0.62 / \\
/ 2.17 \pm 0.44\end{array}$ & $\begin{array}{l}0.064 \\
0.004\end{array}$ \\
\hline $\begin{array}{l}\text { Dissimilarity in the auricular surfaces } \\
\text { position and/or size }\end{array}$ & $3 / 31$ & $8 / 19$ & $0.015^{*}$ & $11 / 22$ & $0.001^{* *}$ \\
\hline $\begin{array}{l}\text { Dissimilarity in the articular facets } \\
\text { position and/or size }\end{array}$ & $14 / 31$ & $9 / 19$ & 0.991 & $10 / 22$ & 0.862 \\
\hline
\end{tabular}

All measurements are in square centimetres with standard deviations; $p$ values indicate the test of significance for difference of means between normal sacra and sacra with articular fusion of $L 5(*)$ and between normal sacra and sacra with osseous fusion of $L 5\left(^{* *}\right)$

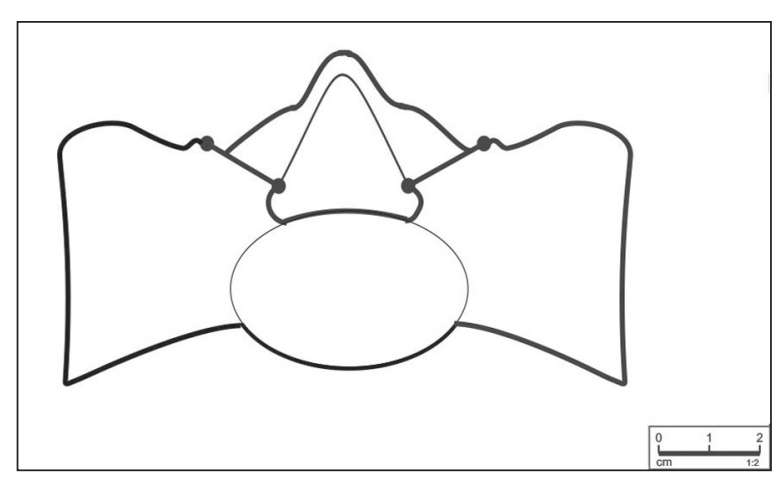

Figure 3. Illustration of the sacral base in sacrum with articular fusion of the last lumbar vertebra. (Sacral base configuration, position and orientation of the superior articular facets are presented).
From 9 specimens with dissimilarity in the superior articular facets size and/or position, 5 presented unilateral accessory articulation. Nineteen sacra with 6 segments showed bilateral complete osseous fusion of the last lumbar vertebra. In all specimens osseous fusion involved vertebral bodies, transverse and costal elements. Three samples presented unilateral osseous fusion with enlarged and elevated auricular surface on the fusion side. Both midventral lengths, straight and curved (VCL, VSL) were greater in these sacra (including the fused last lumbar vertebra), so the $\mathrm{LCl}$ was almost similar to that in normal samples. The value of SBDI indicated longer than wide sacral bodies (Table 1). 


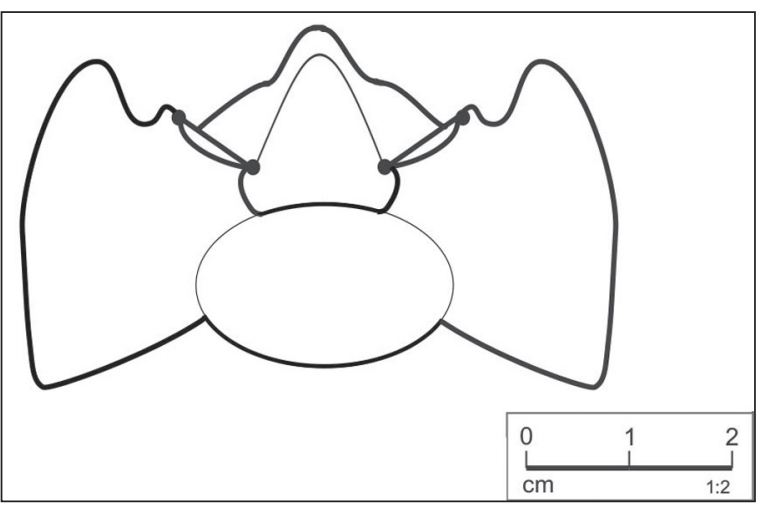

Figure 4. Illustration of the sacral base in sacrum with osseous fusion of the last lumbar vertebra. (Sacral base configuration, position and orientation of the superior articular facets are presented).

In most samples only the ventral sloping half of the newly formed first sacral segment bore at its sides auricular surfaces. The craniodorsal edges of the auricular surfaces were moved forward bellow the plane of the fused lumbar vertebra. The wedging non-articular part was enlarged and occupied the dorsal half of the first segment with more pronounced wedging (Fig. 4). The divergence of the superior limbs was more pronounced. Superior limbs were almost vertical; the coalescence of the superior and inferior limbs was low, between the fused lumbar vertebra and the previous first sacral segment, while the inferior limbs ended at the lower level of the second sacral segment. Auricular surfaces were longer than wide (Fig. 5). The upper surface in these sacra was the least modified from the typical lumbar vertebra. The superior articular facets were slightly more close oriented against the midsagittal plane and more distanced from the vertebral body. The depth of the lateral recesses part of the sacral canal was greater (Table 2). The articular surface areas on the superior articular processes were increased, mostly concave (Table 3). Most of the articular processes bore on their lateral aspects rough areas homologous with the lumbar mammillary processes. Most expressed dissimilarity in the auricular size and position was notified in sacra with unilateral osseous fusion. A rudimentary facet was always notified on the side of osseous fusion.

\section{DISCUSSION}

Morphostructural modifications of the lumbosacral region in sacralisation may alter its biomechanical properties. The sacrum is massive in the bodies and transverse elements of its upper 2 to 3 segments
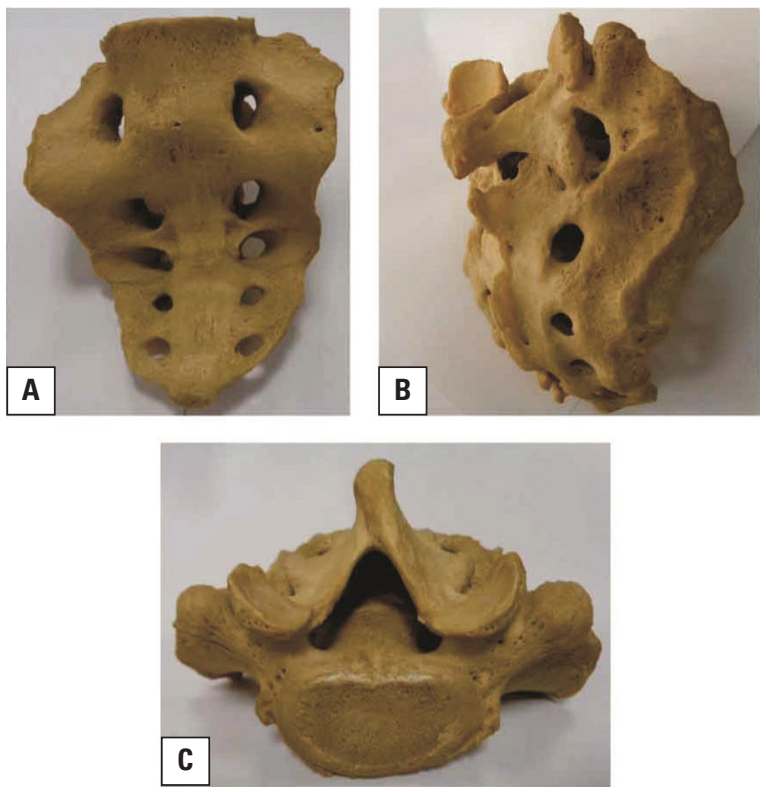

Figure 5. A. Ventral view of sacrum with osseous fusion of the last lumbar vertebra; B. Note the elevation of the auricular surface to the midlevel of the fused vertebra and large roughen area for ligamentous attachments behind; C. Sacral base of the same sacrum.

designed to allow it to be locked into the pelvic griddle, transfer axial forces into the lower limbs and resist shearing from vertical compression. Current research established sacroiliac joints stability on a model based on force and form closure. Efficient transfer of load is provided by myofascial-ligamentous force closing, especially from an extracapsular dorsally located synarthrosis augmented by sacroiliac ligaments. The structural features that contribute sacroiliac joint stability through "form closure" include the configuration of interfacing auricular surfaces, dorsocranial wedging of sacrum and the complementary ridges and grooves of the articular surfaces [19]. Biomechanical calculations showed that high friction coefficients and great wedge angle of sacrum increase the stability of the sacroiliac joints $[21,22]$. The wedge shaping of sacrum prevents it to tilt forwards and downwards under vertical loads remaining the sacrum clamped between the ilia. In contrast to the sacrum and its base, the superior limbs of the auricular surfaces diverge to one another. The reported mean angle of the auricular surfaces of 10 sacra of older specimens was $40^{\circ}$ at $\mathrm{S} 1,25^{\circ}$ at $\mathrm{S} 2$ and $-10^{\circ}$ at S3 [7]. Our results showed that the divergence of the superior and the convergence of the inferior limbs of the auricular surfaces was less pronounced in sacra with articular fusion of $L 5$, changing their 
configuration. The non-articular wedging part of the sacrum incorporated into the ilia was reduced as well. Sacroiliac joint surfaces are anatomical structures that supply passive stability designed to provide bony locking mechanism with the two ilia. Such morphologic alterations compromise the stability of the sacroiliac joints. These modifications are probably in relation to development of additional supporting mechanism like accessory articulations on the dorsal part of the sacral base. In contrast to the sacra with articular fusion of L5, in osseously fused sacra the proportion between the articular and the wedging non-articular part was changed in favour of the wedging part. Reduced articular part of the first segment was compensated by slightly more pronounced divergence of the superior limbs and wider wedged posterior area for ligamentous attachment. Development of additional supporting mechanisms in transitory sacra contributes to achieving balance of "form closure" and "force closure" in order to maintain the stability of sacroiliac joints. In females the reported average auricular surface area ranged from $10.7 \mathrm{~cm}^{2}$ to $14.2 \mathrm{~cm}^{2}[7,18]$. Our results demonstrated significant variability in auricular size and position in sacra with osseous and articular fusion of the last lumbar vertebra. Other authors also reported significant intra-individual variation (left-right) in auricular surfaces size and considerable interindividual size variability $[8,23]$. The process of fusion of the last lumbar vertebra with the sacrum is conjoined with elevation of the auricular surfaces, but the position of the sacroiliac joints against the last mobile functional spinal unit is modified in different way in sacra with articular fusion vs. sacra with osseous fusion of L5. In articular fusion the dorsal parts of the sacroiliac joints are elevated above the level of the last mobile segment, while in osseous fusion they are replaced below the level that became last mobile level due to the complete assimilation process. The number of lumbar vertebra was reduced as well. Because of the forward slope of the sacral vertebral body surface, there is a constant tendency for L5 to slide forwards down this slope influenced by the body weight. The lumbar and the lumbosacral zygapophyseal joints provide locking mechanism that resist forward displacement. Mahato $[11,12]$ reported that in sacra with accessory articulations the superior articular facets were more coronally oriented and flat. This orientation provides greater resistance to forward displacement but less resistance to axial rotation. In sacra with osseous fusion of L5 more sagittally oriented superior articular facets provide less protection against forward displacement, while the resistance to axial rotation is greater. Facet tropism was common finding in sacra with unilateral articular fusion of L5. It has been reported that facetogenic low back pain could arise from a contralateral transitional vertebra of type II (articular fusion) [3]. In contrast to the osseously fused sacra, the depth of the lateral recesses was reduced in sacra with accessory articulations raising the possibility for the nerve roots to be compressed by structural alterations in one or other of the structures that form boundaries to the recesses. The association of lumbosacral transitional vertebra pseudoarthrosis and S1 nerve root entrapment has been reported $[2,14]$. The complete osseous fusion affects mostly the last mobile spinal level, or the level above the osseously fused lumbar vertebra [15, 16]. Relative hypermobility and greater degree of stress at this level results in severe discopathy and arthropathy $[1,5,10,17]$.

\section{CONCLUSIONS}

Sacra with articular fusion were associated with characteristic morphologic alterations different from that of sacra with osseous fusion of the last lumbar vertebra. The term "sacralisation" includes both types of assimilation with mutually different morphostructural characteristics in contrast to the normal sacra. Analysis of their morphologic alterations may help in understanding the different biomechanical properties and patterns of load transmission.

\section{REFERENCES}

1. Aihara $\mathrm{T}$, Takahashi $\mathrm{K}$, Ogasawara A, Itadera $\mathrm{E}$, Ono $\mathrm{Y}$, Moriya H (2005) Intervertebral disc degeneration associated with lumbosacral transitional vertebrae: a clinical and anatomical study. J Bone Joint Surg $\mathrm{Br}, 87$ : 687-691.

2. Bezuidenhout AF, Lotz JW (2014) Lumbosacral transitional vertebra and S1 radiculopathy: the value of coronal MR imaging. Neuroradiology, 56: 453-457.

3. Brault JS, Smith J, Currier BL (2001) Partial lumbosacral transitional vertebra resection for contralateral facetogenic pain. Spine (Phila Pa 1976), 26: 226-229.

4. Bron JL, van Royen BJ, Wuisman PI (2007) The clinical significance of lumbosacral transitional anomalies. Acta Orthop Belg, 73: 687-695.

5. Brown MF, Rockall AG, Hallam P, Hall-Craggs MA, Edgar MA (2000)Transitional lumbosacral vertebrae: incidence of disc degeneration above and below. J Bone Joint Surg Br, 82-B (Suppl II): 180. 
6. DelportEG, Cucuzzella TR, Kim N, MarleyJ, Pruitt C, DelportAG (2006) Lumbosacral transitional vertebrae: incidence in a consecutive patient series. Pain Physician, 9: 53-56.

7. Dijkstra PF, Vleeming A, Stoeckart R (1989) Complex motion tomography of the sacroiliac joint. An anatomical and roentgenological study. Rofo, 150: 635-642.

8. Ebraheim NA, Biyani A (2003) Percutaneous computed tomographic stabilization of the pathologic sacroiliac joint. Clin Orthop Relat Res, 408: 252-255.

9. Konin GP, Walz DM (2010) Lumbosacral transitional vertebrae: classification, imaging findings, and clinical relevance. Am J Neuroradiol, 31: 1778-1786.

10. Luoma K, Vehmas T, Raininko R, Luukkonen R, Riihimäki H (2004) Lumbosacral transitional vertebra : relation to disc degeneration and low back pain. Spine (Phila Pa 1976), 29: 200-205.

11. Mahato NK (2010) Morphometric analysis and identification of characteristic features in sacra bearing accessory articulations with L5 vertebra. Spine J, 10: 616-621.

12. Mahato NK (2011) Facet dimensions, orientation and symmetry at L5-S1 junction in lumbosacral transitional states. Spine (Phila Pa 1976), 36: E569-E573.

13. Nardo L, Alizai H, Virayavanich W Liu F, Hernandez A, Lynch JA, Nevitt MC, McCulloch CE, Lane NE, Link TM (2012) Lumbosacral transitional vertebrae: association with low back pain. Radiology, 265: 497-503.

14. Otani K, Konno S, Kikuchi S (2001) Lumbosacral transitional vertebrae and nerve-root symptoms. J Bone Joint Surg Br, 83: 1137-1140.

15. Quinlan JF, Duke D, Eustace S (2006) Bertolotti's syndrome. A cause of back pain in young people. J Bone Joint Surg $\mathrm{Br}$, 88: 1183-1186.
16. Taskaynatan MA, Izci Y, Ozgul A, Hazneci B, Dursun H, Kalyon TA (2005) Clinical significance of congenital lumbosacral malformations in young male population with prolonged low back pain. Spine, 30: E210-E213.

17. Vergauwen S, Parizel PM, Van Breusegem L, Van Goethem JW, Nackaerts Y, Van den Hauwe L, De Schepper AM (1997) Distribution and incidence of degenerative spine changes in patients with a lumbosacral transitional vertebra. Eur Spine J, 6: 168-172.

18. Vleeming A, Buyruk HM, Stoeckart R Karamursel S, Snijders CJ (1992a) An integrated therapy for peripartum pelvic instability: a study of the biomechanical effects of pelvic belts. Am J Obstet Gynecol, 166: 1243-1247.

19. Vleeming A, Schuenke MD,Masi AT, Carreiro JE, Danneels L, Willard FH (2012) The sacroiliac joint: an overview of its anatomy, function and potential clinical implications. J Anat, 221: 537-567.

20. Vleeming A, Stoeckart R (2007) The role of pelvic girdle in coupling the spine and the legs. In: Movement, stability and lumbopelvic pain: Integration and research. Churchill Livingstone, Edinburgh, pp. 113-137.

21. Vleeming A, Stoeckart R, Volkers AC, Snijders CJ (1990a) Relation between form and function in the sacroiliac joint. Part I: clinical anatomical aspects. Spine (Phila Pa 1976), 15: 130-132.

22. Vleeming A, Volkers AC, Snijders C, Stoeckart R, (1990b) Relation between form and function in the sacroiliac joint. Part II: biomechanical aspects. Spine (Phila Pa 1976), 15: 133-136.

23. Vleeming A, Van Wingerden JP, Dijkstra PF, Stoeckart R, Snijders CJ, Stijnen T (1992b) Mobility in the sacroiliac joints in the elderly: a kinematic and radiological study. Clin Biomech, 7: 170-176. 